\title{
Biodiversity of wild alfalfa pollinators and their temporal foraging characters in Hexi Corridor, Northwest China
}

\author{
Xiaojuan Wang, Hongping Liu, Lichun Huang, Shuzhen Zhang, Zhigang Deng, Jing Li \\ \& Liang Jin*
}

\begin{abstract}
Wang, X., Liu, H., Huang, L., Zhang, S., Deng, Z., Li, J. \& Jin, L. 2012: Biodiversity of wild alfalfa pollinators and their temporal foraging characters in Hexi Corridor, Northwest China. — Entomol. Fennica 23: 4-12.

Seed production of alfalfa (Medicago sativa L.) is important in determining the effective distribution of new cultivars to farmers. However, little is known about the biodiversity and their community function of native wild pollinators of alfalfa in agronomic systems. We investigated the biodiversity of insects which visited alfalfa flowers and their temporal foraging characters in Hexi Corridor, China. A high biodiversity of insect visitors was discovered, 20 insect taxa in all, including 13 species of Hymenoptera, 3 species of Coleoptera, 3 species of Lepidoptera and 1 species of Diptera. Three native bee species, Andrena squamata, Anthophora melanognatha and Megachile abluta, were validated as the principal pollinators. They showed significant variations in tripping mode and their diurnal distribution patterns. Our results indicated that the native wild bees are diverse and they complement each other. This means they have developed a more complex system for the pollination of alfalfa than has been previously found out.
\end{abstract}

\begin{abstract}
X. Wang, L. Huang, S. Zhang, Z. Deng, J. Li \& L. Jin, School of Pastoral Agriculture Science and Technology, Lanzhou University, P.O Box 61, Lanzhou 730020, China; * Corresponding author's e-mail: liangjin@lzu.edu.cn

H. Liu, School of Pastoral Agriculture Science and Technology, Lanzhou University, P.O Box 61, Lanzhou 730020 \& China School of Lintao Agricultural Science, Dingxi 730050, China
\end{abstract}

Received 10 November 2010, accepted 20 October 2011

\section{Introduction}

Pollinators are important in $35 \%$ of global crop production (Klein et al. 2007), and multiple pollinators vary in visitation rates, pollen removal and deposition, spatial and temporal distribution for their visitation behaviors (Sahli \& Jeffrey 2007). Diverse pollinator assemblages may impose complex selection and thus limit specialization to particular pollinators (Thompson 2001). The rates of pollinator visitations may vary with different floral features, e.g. flower color (Staton
1987), size (Conner \& Rush 1996, Abraham 2005), nectar production (Mitchell 1994) and display morph (de Jong \& Klinkhamer 1994, Thompson 2001) etc. Insect visitation may also be sconsiderably influenced by the spatial and temporal arrangement of floral traits (Campbell et al. 1997, Mitchell et al. 2004), and this interaction is likely to be particularly important since different pollinators often show marked spatialtemporal variation in abundance (Herrera 1988) and pollination effectiveness (Wilson \& Thomson 1991). 
Information on how the different insect types visiting one single plant species differ in their response to plant reproductive traits is nevertheless important in order to quantify the diversity and ecological community structure between a plant and its generalist pollinator fauna (Thompson 2001). However, little is known about variation in pollination services to a single plant species (Price et al. 2004). Most of the pollination biology over the past few decades focused on a single plant or pollinator species, whereas a focus at the level of the entire pollinator community was uncommon.

Alfalfa (Medicago sativa L.) is one of the most important perennial legume crops and a superior source of forage due to its high nutritional quality and herbage yield (Li \& Brummer 2009, Keivani et al. 2010, Wang et al. 2011). As a typical leguminous flower, alfalfa depends on a process known as "tripping" for its pollination (Viands et al. 1988). Because of the unique relationship between its flower structure and its pollination requirements, most studies have focused on the relative merits of honey bees (Nabhan \& Buchmann 1997), leafcutter bees (Bosch \& Kemp 2005) and alkali bees (Alan \& Wooten 1987) etc. Pollination systems involving solitary bees and flowers are of particular interest, because it is possible to correlate bee foraging behavior directly with reproductive output of both the plant (through seed set) and the bee (through the pollen and nectar in a provision mass). A simple pollination model for understanding the reproductive output of alfalfa and its solitary bee pollinator, the leafcutter bee (Megachile rotundata), was studied looking at seed yield (Strickler 1996). The composition of alfalfa pollen loads for leafcutter bees (O’Neill et al. 2004), population dynamics and foraging behavior of $M$. rotundata, as well as alfalfa bloom and pollination rates in two fields in Eastern Oregon (Bosch \& Kemp 2005), have also been studied.

Because of the relatively few information that exists on the status of pollinators or pollination function (Kremen et al. 2007), concerns about the loss of pollinators and the services they provide have grown over the last decades (Kearns et al. 1998). Only few studies have examined the biodi- versity and relationships of different native wild insect types on alfalfa in an agronomic system. The exception is Cane (2002), who selected five commercial bee species to study their floral tripping frequencies. In particular, little is known about the variation of wild insects and their interspecific relationship with ecological factors in adverse environments.

The aim of this research was to evaluate the biodiversity of the pollinating insects in an alfalfa agronomic system, the pollinator's functions and their ecological niche at the community level in an arid region. For this purpose, we chose Hexi Corridor, an arid area of Northwest China, as our study site. Hexi Corridor is a narrow terrestrial ecosystem between the Badain Jaran Desert and the Tibetan Plateau. It is famous for having plenty of sunshine, little precipitation and other suitable conditions for alfalfa seed production. However, to date there have been few reports on the pollination biology of alfalfa in this region (Wang et al. 2009). We conducted two field studies. The objective of the first study was to investigate the biodiversity of visiting insects to alfalfa flowers. The objective of the second study was to discover the foraging behaviors of different principal pollinators and their relationship at community level.

\section{Material and methods}

\subsection{Study site}

This study was carried out in Lanzhou University Ecological Research Area (Linze experiment station, $39^{\circ} 21^{\prime} \mathrm{N}, 100^{\circ} 07^{\prime} \mathrm{E}$, altitude $1,367 \mathrm{~m}$ ) in the middle of Hexi Corridor, Northwest China from May to June in 2005, 2006 and 2007. This area is characterized by an arid climate and scarce rainfall. The annual precipitation is $117 \mathrm{~mm}$, with the evaporation at $2,390 \mathrm{~mm}$ per year. It is dry and hot in summer but cold in winter. On average, there are 2,869-3,282 hours of sunshine annually and the average temperature in this region is $7^{\circ} \mathrm{C}$. In this site, length of the growing season in the region is 145 days. The local agriculture system mostly depends on the underground water tillage system. 
Table 1. List of visiting insect species of alfalfa from 8:00 a.m. to 6:00 p.m. during the flowering peak in Hexi Corridor, Northwest China from 2005 to 2007.

\begin{tabular}{|c|c|c|c|c|}
\hline \multirow[t]{2}{*}{ Order } & \multirow[t]{2}{*}{ Insect species } & \multicolumn{3}{|c|}{ No. of insects visiting per day } \\
\hline & & 2005 & 2006 & 2007 \\
\hline \multirow[t]{13}{*}{ Hymenoptera } & Andrena squamata & 1,944 & 1,960 & 1,912 \\
\hline & Anthophora melanognatha & 3,280 & 3,272 & 3,320 \\
\hline & Megachile abluta & 158 & 152 & 160 \\
\hline & Megachile spissula & 165 & 184 & 176 \\
\hline & Xylocopa valga & 0 & 38 & 42 \\
\hline & Proxylocopa nitidiventris & 35 & 42 & 38 \\
\hline & Proxylocopa xinjiangensis & 0 & 65 & 0 \\
\hline & Eucera pekingensis & 0 & 80 & 0 \\
\hline & Apis sinensis & 32 & 0 & 0 \\
\hline & Anthidium florentinum & 51 & 40 & 56 \\
\hline & Bombus agrorum & 0 & 0 & 28 \\
\hline & Polistes olivaceus & 0 & 0 & 24 \\
\hline & Ammophila infesta & 0 & 49 & 56 \\
\hline \multirow[t]{3}{*}{ Lepidoptera } & Artogeia (Pieris) rapae & 18 & 22 & 16 \\
\hline & Zizeeria spp. & 24 & 35 & 32 \\
\hline & Heliothis dipsace & 10 & 15 & 14 \\
\hline \multirow[t]{3}{*}{ Coleoptera } & Mylabris calida & 18 & 16 & 10 \\
\hline & Lytta caraganae & 0 & 0 & 12 \\
\hline & Coccinella septempunctata & 14 & 18 & 20 \\
\hline Diptera & Epistrophe balteata & 17 & 0 & 18 \\
\hline
\end{tabular}

\subsection{Plant material}

One cultivated alfalfa population was selected and the seeds were sown in April, 2003. The study was performed in an alfalfa field $\left(970 \mathrm{~m}^{2}\right)$ from 2005-2007. The flowering time of alfalfa is from the middle of May to late July and pods become ripe in the autumn (Wang et al. 2009). Each stem of alfalfa terminates in a raceme or cluster of 10 to 30 purple florets.

\subsection{Study one: Biodiversity of visiting insects}

The insects visiting alfalfa flowers were recorded from 8:00 a.m. to 8:00 p.m. for four consecutive days per year during the flowering peak from $15^{\text {th }}$ June to $18^{\text {th }}$ June in 2005,2006 and 2007. Thirtyminute intervals of the census period were utilized for capturing specimens of the insect visitors using a hand held net. All insects were captured with a sweep net and taken back to lab for identification according to the identification manuals (Wu 1990, Tan et al. 2005, Yang 2005, Wu 2006, Huang \& Cheng 2007).

\subsection{Study two}

\subsubsection{Pollinator's tripping mode}

Based on the results of the study one, the principal pollinators were selected and investigated to discover how these insects tripped alfalfa flowers. Thirty pollinators per bee species were recorded, each representing a replicate. The different methods of "tripping flower" were compared among the different insects.

\subsubsection{Numbers of flower visited per bee}

The numbers of alfalfa flower that one pollinator visited in one-minute period were recorded. Thirty pollinators per bee species were recorded, each representing a replicate. The counts were recorded per each hour separately from 6:00 a.m. to 8:00 p.m. over four consecutive days from $19^{\text {th }}$ June to $22^{\text {th }}$ June in 2007.

\subsubsection{Time of the pollinator landing on a flower}

The landing time of the pollinators were recorded as a bee landed on a flower. Thirty pollinators per 
bee species were recorded, each representing a replicate. The observations were performed every two hours over four consecutive days from $19^{\text {th }}$ June to $22^{\text {th }}$ June in 2007.

\subsection{Statistical analysis}

All the data sets were checked for normality before statistical analysis, and none were found to be significantly different from a normal distribution. Thus, no data transformation was performed. One-way ANOVA was used to test the numbers of alfalfa flower visited per bee and durations of the pollinators landing on an alfalfa flower of the three principal pollinators. Twoway ANOVAs were used to test the effects of the principal pollinators and diurnal effects on the numbers of alfalfa flowers visited per bee. Similarly, the numbers of the principal bees per day and the durations of the pollinator landing on an alfalfa flower were also analyzed with Two-way ANOVAs.

\section{Results}

\subsection{Study one: Biodiversity of visiting insects}

More than 8,620 insect visitors were recorded for the observations in 2005, 2006 and 2007. Twenty insect taxa, including 13 species of Hymenoptera, 3 species of Coleoptera, 3 species of Lepidoptera and 1 species of Diptera, were observed to visit alfalfa flowers (Table 1). Lepidoptera, Coleoptera and Diptera observed in this study were not considered as major pollinators because of their small numbers, erratic visiting frequency, low abundance and no "tripping" process observed for alfalfa flowers. Thus, only the 13 species of Hymenoptera were considered as the effective pollinators.

According to the results, wild bees (as opposed to commercial bees) accounted for $85 \%$ of these visitors (data not shown) and were identified as belonging to 7 different Hymenoptera species (Fig. 1). Among the seven bee species, Andrena squamata (Andrenidae) and Anthophora melanognatha (Apidae) were the two most abundant visitors (Fig. 1). Moreover, the numbers

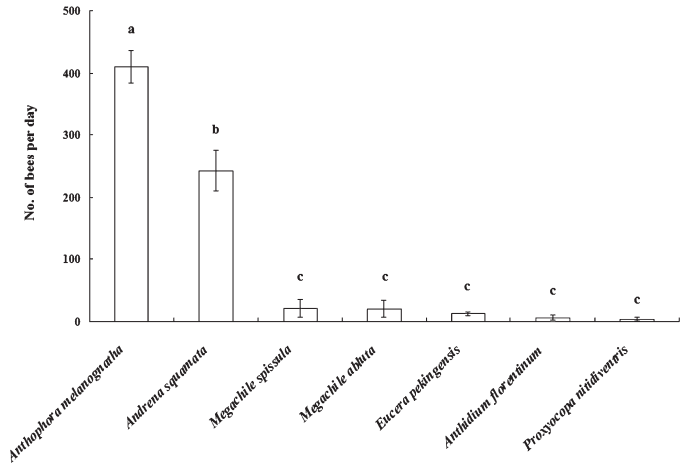

Fig. 1. Means $\pm S D$ of visiting frequency of dominant bee pollinators on alfalfa in Hexi Corridor, Northwest China. Different letters above the bars indicate a significant difference at $P=0.05$.

of Megachile abluta (Megachilidae) were significantly lower when compared to the two dominant bee species above (Fig. 1). However, according to our investigation, M. abluta was good at tripping alfalfa flowers and with a higher efficiency of pollination (unpublished data), so all of these 3 bee species were collectively referred to as the "principal pollinators".

\subsection{Study two}

\subsubsection{Pollinator's tripping mode}

There were significant differences in the diurnal visitation among the three principal bee species to alfalfa flowers (Table 2). This indicated that different bee species may use different tripping modes according to their different body characters, foraging time, collecting feedback (such as honey or pollen), etc. These bees have various pollination modes and these are recorded below.

Andrena squamata is medium-sized with the body length of $10-13 \mathrm{~mm}$. It belongs to shorttongued bee species. After landing on alfalfa flowers, A. squamata pushes the standard petal of alfalfa forward with its head and exerts pressure upon the keel petal and the wing petal with its legs, causing the sexual column to separate. Upon release, the column strikes the standard petal, sometimes striking the underside of the head of the bee first. The column is then released when the bee inserts its proboscis into the flower throat 
Table 2. Two-way ANOVAs for testing the effects of bee species and diurnal subsection (see Fig. 2) on numbers of visiting bees on alfalfa per day, numbers of flowers visited by bees and the landing times of bees on a flower.

\begin{tabular}{|c|c|c|c|c|}
\hline Source of variation & $d f$ & MS & $F$ & $P$ \\
\hline \multicolumn{5}{|c|}{ No. of visiting bees per day } \\
\hline Bee species (B) & 2 & 19117.2 & 293.9 & $<0.001$ \\
\hline Diurnal subsection (D) & 9 & 852.1 & 13.1 & $<0.001$ \\
\hline$B \times D$ & 18 & 459.5 & 7.1 & $<0.001$ \\
\hline Error & 120 & 65.1 & & \\
\hline \multicolumn{5}{|c|}{ No. of flowers visited by bees } \\
\hline Bee species $(B)$ & 2 & 4554.3 & 912.4 & $<0.001$ \\
\hline Diurnal subsection (D) & 9 & 398.4 & 79.8 & $<0.001$ \\
\hline$B \times D$ & 18 & 270.2 & 54.2 & $<0.001$ \\
\hline Error & 570 & 5.0 & & \\
\hline \multicolumn{5}{|c|}{ Landing times of bees on a flower } \\
\hline Bee species $(B)$ & 2 & 290.2 & 143.4 & $<0.001$ \\
\hline Diurnal subsection (D) & 4 & 7.9 & 3.9 & 0.004 \\
\hline$B \times D$ & 8 & 7.6 & 3.8 & $<0.001$ \\
\hline Error & 285 & 2.0 & & \\
\hline
\end{tabular}

to search for nectar or pollen and exerts pressure on the keel petal to lead it separating. After the flower is tripped, the pollen is dusted upon the bee. With pollen on their body hairs, the bees move the pollen to special areas on their hind legs called pollen baskets. Then A. squamata carries the pollen to another alfalfa flower. In our study, A. squamata was the earliest pollinator every day under diurnal observation. We found that 8:3010:00 a.m. was the peak foraging time of this pollinator, followed by 5:00 -7:00 p.m.

Megachile abluta was one of the most important pollinator of alfalfa and it could easily be distinguished from other bees by the presence of a dense, metasomal scopa (present in all females), a broad, rectangular labrum, and two submarginal cells in the forewing. Megachile abluta is a longtongued bee species with the body length of 13$17 \mathrm{~mm}$, and has a different foraging behavior compared to the other two main bee species of this study. The upper inflorescences were tripped by its head and the pollen and nectar were selected first. To the lower inflorescences, $M$. abluta exerted pressure with its body on the keel petal and wing petal, causing them to separate. In our study, the time of appearance for this bee species was from 11:00 a.m. to 2:00 p.m. This was the period of the highest daily temperature and had the most flowers "tripped". Perhaps high temperature allows the flowers to be tripped more easily.
Anthophora melanognatha is relatively small, 8-11 $\mathrm{mm}$ long, and belongs to longtongued bee species too. It often sucked nectar from the basal part of flower by pushing its head into the side of the flower for a long time with a headstand pose. For this bee species, no "tripping" happened before 10:00 a.m. But as the temperature rose, the tripping process was observed and the foraging behavior was similar to A. squamata. According to our observations, the foraging activity of this bee species was mainly from 10:30 to $12: 30$ a.m. and from 4:30 to $6: 30$ p.m.

\subsubsection{Numbers of inflorescences visited per bee}

There were significant differences in the numbers of visited flowers per bee among $A$. squamata, $M$. abluta and A. melanognatha (Table 2). Among the three principal pollinators, $M$. abluta had the highest numbers of visiting bees to alfalfa flowers in daytime (Fig. 2), indicating that M. abluta was one of the most important pollinator of alfalfa in the Hexi Corridor with a high "tripping" efficiency. There was no $M$. abluta at 8:30 a.m., so M. abluta may be adapted to high temperatures.

\subsubsection{Time of pollinator landing on a flower}

There were significant differences between the landing times of pollinators on flower among the three principal bee species (Table 2). It was the 
Fig. 2. Means $\pm S D$ of numbers of alfalfa flowers visited per bee by the three principal pollinators in Hexi Corridor, Northwest China.

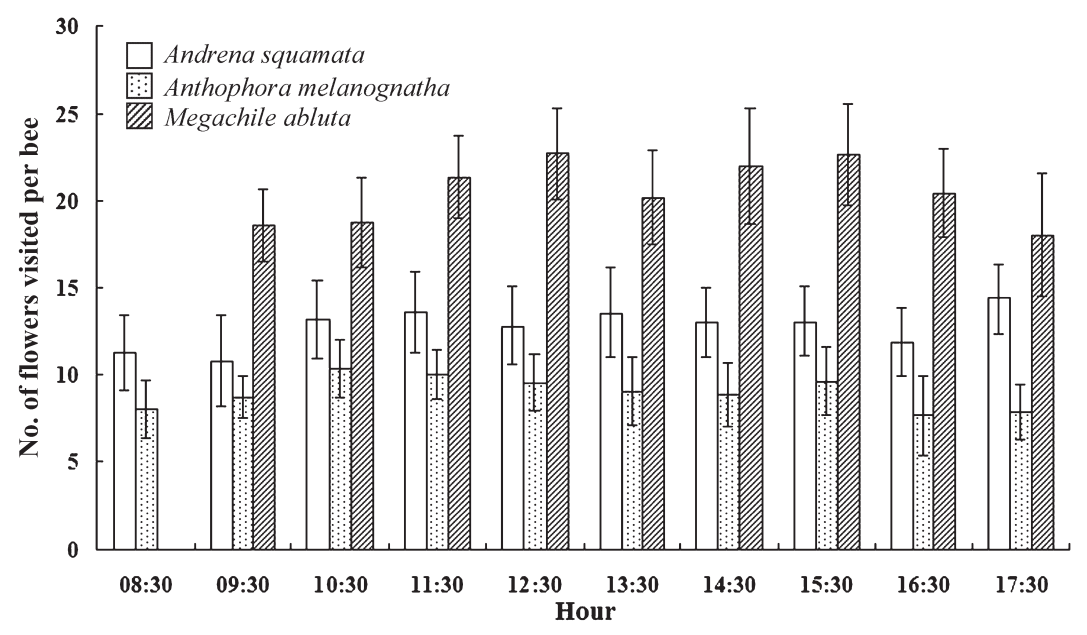

Fig. 3. Means $\pm S D$ of times of pollinator landing on an alfalfa flower in Hexi Corridor, Northwest China.

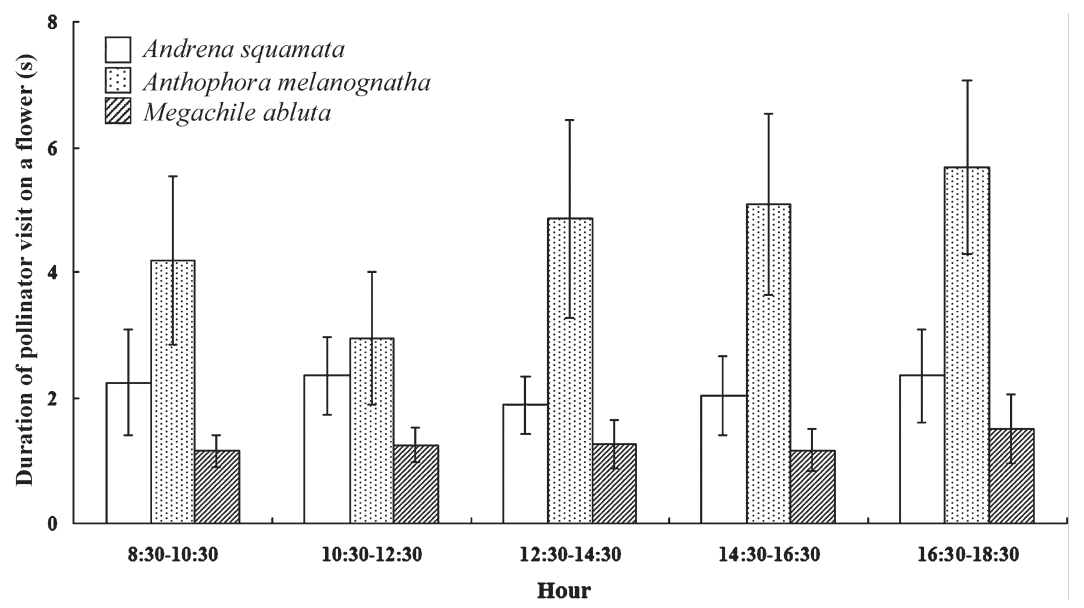

shortest for M. abluta and the longest for A. melanognatha (Fig. 3). The results suggested that perhaps less time spent by a pollinator landing on flower led to a higher frequency of visits to alfalfa flowers.

\section{Discussion}

\subsection{Diversity and abundance of pollinators of $M$. sativa in the arid region}

Floral visitors are seldom equivalent as pollinators and can differ markedly in their abilities to transfer pollen to host plant stigmas (Cane \& Schiffhauer 2003) and in their frequencies of host visitation. In this case, we discovered that the pollination of alfalfa, which is required for seed pro- duction, mainly depends on the services of bees, which accounted for $85 \%$ of the total visitors (Fig. 1). It is not surprising that at a global scale, bees are most diverse in arid and semi-arid regions, such as the Mediterranean basin, Central Asia, the southwestern deserts of North America, arid regions of Chile and Argentina, temperate parts of Australia, and southern Africa (Michener 1979). Although it is clear that all these wild bee species live in natural and semi-natural habitats, most of them are unknown and have not been systematically studied. Some wild bee species of this study have not been recorded as alfalfa pollinators before, such as Ammophila infesta, Polistes olivaceus and Bombus agrorum (Table 1), meaning that there may be more complexity in this insect guild than we formerly regarded. It has been reported that a greater diversity of wild bee 
species including native Megachile species also pollinated alfalfa well in North American (O’Neill et al. 2004, Bosch \& Kemp 2005). And this greater diversity may mean that some of these insects may not be dominant pollinators, but may provide other benefits to alfalfa, such as increased plant growth, enhanced plant fitness and higher promotion of plant-herbivore mutualisms (Belsky 1986). The functions of these insects for alfalfa pollination should be further studied, especially estimating the role of different species in the pollinator guild.

Extensive losses in pollinator guilds and communities can disrupt ecosystem integrity, and nowadays most farmers rely on honey bees in most of the fruit and seed production (Klein et al. 2003, Losey \& Vaughan 2006), and this is also true for alfalfa (Kevan \& Phillips 2001). It has been demonstrated that only few remaining generalist pollinators will ensure pollination services in the future (Ghazoul 2005). However, even crops with generalized pollination systems have been shown to profit from high pollinator diversity (Klein et al. 2003), and specialized crops can be expected to rely more on diverse pollinator assemblages. Although both the abundance and diversity of wild bee communities are associated with increased crop pollination, wild bee diversity predicts crop production better than wild bee abundance (Kremen et al. 2004). Our results showed that there was high diversity of wild bee species in the Hexi corridor, and hence, may benefit alfalfa through improved reproductive success. On the basis of these results, we suggest that further study should be carried out and in more detail on wild bee species and their life-cycles, distribution and population trends, especially on their potential as pollinators. It should also be studied to which extent different diversities and amounts of wild bees result to increased seed production of alfalfa in the Hexi corridor.

\subsection{Temporal inter-specific relationship}

The dominant wild bee species visiting alfalfa showed significant difference in diurnal distribution patterns. In this study, $A$. squamata and $A$. melanognatha visited alfalfa in early morning and late afternoon, but M. abluta visited at noon between 11:00-14:00. The reason for this pattern is not immediately clear, although it is likely that the diurnal temperature, light and humidity were responsible for the change in foraging activity (Wang et al. 2009). The ethology of the pollinators was found to be influenced by the prevailing weather conditions during pollination (Martiniello et al. 2003). Food collection requires an enormous expenditure of energy, and flight activity accounts for by far the greatest share of energy consumption (Louis et al. 2005). The reason the flowers open early in the morning and are visited mainly by large insects may be because foraging at low temperature is expensive energetically. Large insects may have a stronger ability to adapt in these conditions. However, our findings suggest that diurnal foraging patterns of different bees visiting the host plant (M. sativa in this case) might be influenced by both the internal factors of bees and the environmental factors (Rocha et al. 2006). Perhaps higher temperature leads to tripping of flowers more easily, so the principal pollinator $M$. abluta with a larger body size may become active when temperature rises and humidity reduces at noon.

In our study, there were also significant differences in the numbers of inflorescences visited per bee among the three principal bee species (Table 2). Megachile abluta visited more alfalfa flowers than A. squamata and A. melanognatha (Fig. 2), mainly because its landing times on an inflorescence were shorter than in the two other bee species (Fig. 3). Because of the smaller body size, $A$. squamata and $A$. melanognatha visiting flowers in early morning and late afternoon may relate to high humidity conditions in which it is easy for pollen to adhere and be transported (Bakker 1989). Thus, our results suggested that M. abluta maybe the dominant species for tripping and $A$. squamata and $A$. melanognatha for pollen transfer. It is also possible that the different pollinators may dominate various ecological niches by visiting flowers at a different time each day, and thus could reduce the inter-specific competition among different insects. On the basis of this opinion, the behaviors of the three dominant bees could be a benefit for themselves, and the biodiversity, sustainability and stability of the insect community (Potts et al. 2006). It may also be that plant species could use resource partitioning (pol- 
len and nectar) and character displacement to regulate the behavior of insects, such as visiting time and visiting frequency etc. By these means, alfalfa can escape intra-specific competition by utilizing different pollinator species, and also could reduce inter-specific competition among pollinators (Wang et al. 2009). The diurnal distribution between the main pollinators in our study may be effective in reducing the competition on the alfalfa flower resources between the pollinators, which concurs with previous works. These state that the species composition of a bee community may affect pollination outcomes, because behavioral interactions among species may alter the pollination efficiency of some plants (Thomson \& Thomson 1992).

Many papers which have focused on pollination systems involving different native bees and flowers are of particular interest, because it is possible to correlate bee foraging behavior directly with reproductive output of both the plant (through seed set) and the bee (through the pollen and nectar in a provision mass) (Strickler 1996). Our results provide evidence for high diversity in wild bee species in adverse habitats and showed that inter-specific relationships between those insects are complementary for each other. However, more comparative studies will be needed to explore how the three main pollinators, $M$. abluta, A. squamata and A. melanognatha, complement each other and finally contribute to alfalfa seed production. To understand to what extent different flower-visitors contribute to pollination, future studies should be aimed at assessing the foraging efficiencies of these insects and their inter-specific differences in relationship between ecological factors and floral display in adverse environments. Long term studies taking evolution into account would be useful. For alfalfa seed production, it should be paid more attention to the diversity of the native wild bees and their complementary relationship to develop a complex pollination system instead of a single bee species.

Acknowledgements. We thank Heather Rumble from Royal Holloway University of London for helping to revise the manuscript. This study was supported by National Basic Research Program of China (2007CB108904), and Fundamental Research Funds for the Central Universities of Lanzhou University (lzujbky-2010-1).

\section{References}

Abraham, J. N. 2005: Insect choice and floral size dimorphism: sexual selection or natural selection? - Journal of Insect Behavior 18: 743-756.

Alan, L.O. \& Wooten, D. B. 1987: Bee pollination and productivity growth: the case of alfalfa. - American Journal of Agricultural Economics 69: 56-63.

Bakker, I. C. 1989: The effects of air humidity on flowering, fruit set, seed set and fruit growth of glasshouse sweet pepper (Capsicum annuum L.). - Scientia Horticulturae 40: $1-8$.

Belsky, A. J. 1986: Does herbivory benefit plants? A review of the evidence. - American Naturalist 127: 870 892.

Bosch, J. \& Kemp, W. P. 2005: Alfalfa leafcutting bee population dynamics, flower availability, and pollination rates in two Oregon alfalfa fields. - Journal of Economic Entomology 98: 1077-1086.

Campbell, D. R., Waser, N. M. \& Meléndez-Ackerman, E. J. 1997: Analyzing pollinator mediated selection in a plant hybrid zone: hummingbird visitation patterns on three spatial scales. - American Naturalist 149: 295315.

Cane, J. H. 2002: Pollinating bees (Hymenoptera: Apiformes) of U.S. alfalfa compared for rates of pod and seed set. - Journal of Economic Entomology 95: 22-27.

Cane, J. H. \& Schiffhauer, D. 2003: Dose-response relationships between pollination and fruiting refine pollinator comparisons for cranberry (Vaccinium macrocarpon [Ericaceae]). - American Journal of Botany 90: $1425-1432$.

Conner, J. K. \& Rush, S. 1996: Effects of flower size and number on pollinator visitation to wild radish, Raphanus raphanistrum. — Oecologia 105: 509-516.

de Jong, T. G. \& Klinkhamer, P. G. L. 1994: Plant size and reproductive success through female and male function. - Journal of Ecology 82: 399-402.

Ghazoul, J. 2005: Buzziness as usual? Questioning the global pollination crisis. - Trends in Ecology and Evolution 20: 367-373.

Herrera, C. M. 1988: Variation in mutualisms: the spatiotemporal mosaic of an insect pollinator assemblage. - Biological Journal of the Linnean Society 35: 95125.

Huang, C. M. \& Cheng, X. Y. 2007: Fauna sinica, Insecta, Diptera, Syrphidae. - Science Press. Beijing, China. 223 pp.

Kearns, C. A., Inouye, D. W. \& Waser, N. M. 1998: Endangered mutualisms: the conservation of plant-pollinator interactions. - Annual Review of Ecology and Systematics 29: 83-112.

Keivani, M., Ramezanpour, S. S., Soltanloo, H., Choukan, R., Naghavi, M. \& Ranjbar, M. 2010: Genetic diversity assessment of alfalfa (Medicago sativa L.) populations using AFLP markers. - Australian Journal of Crop Science 4: 491-497.

Kevan, P. G. \& Phillips, T. P. 2001: The economic impacts of pollinator declines: an approach to assessing the consequences. - Conservation Ecology 5: 8 [www 
document] URL http://www.consecol.org/vol5/iss1/ $\operatorname{art} 8 /$

Klein, A. M., Steffan-Dewenter, I. \& Tscharntke, T. 2003: Fruit set of highland coffee increases with the diversity of pollinating bees. - Proceedings of the Royal Society B Biological Sciences 270: 955-961.

Klein, A. M., Vaissière, B. E., Cane, J. H., Steffan-Dewenter, I., Saul, A. C., Kremen, C. \& Tscharntke1, T. 2007: Importance of pollinators in changing landscapes for world crops. - Proceedings of the Royal Society B Biological Sciences 274: 303-313.

Kremen, C., Williams, N. M., Bugg, R. L., Fay, J. P. \& Thorp, R. W. 2004: The area requirements of an ecosystem service: crop pollination by native bee communities in California. - Ecology Letters 7: 1109-1119.

Kremen, C., Williams, N., Aizen, M. A., Gemmill-Herren, B., LeBuhn, G., Minckley, R., Packer, L., Potts, S., Roulston, T., Steffan-Dewenter, I., Vazquez, D., Winfree, R., Adams, L., Crone, E., Greenleaf, S., Keitt, T., Klein, A. M., Regetz, J. \& Ricketts, T. 2007: Pollination and other ecosystem services produced by mobile organisms: a conceptual framework for the effects of land use change. - Ecology Letters 10: 299-314.

Li, X. H. \& Brummer, E. C. 2009: Inbreeding depression for fertility and biomass in advanced generations of inter- and intrasubspecific hybrids of tetraploid alfalfa. - Crop Science 49: 13-19.

Losey, J. E. \& Vaughan, M. 2006: The economic value of ecological services provided by insects. - BioScience 56: 311-323.

Louis, M. S., Loon, J. J. A. \& Marcel, D. 2005: Insect-plant biology. — Oxford University Press, New York. 316 pp.

Martiniello, P., Iannucci, A. \& Pinzauti, M. 2003: Behavior of solitary pollinators and their effect on berseem and alfalfa seed yield and yield components in Mediterranean environments. - Journal of New Seeds 5: $17-27$.

Michener, C. D. 1979: Biogeography of the bees. - Annals of the Missouri Botanical Garden 66: 277-347.

Mitchell, R. J. 1994: Effects of floral traits, pollinator visitation, and plant size on Ipomopsis aggregata fruit production. - American Naturalist 143: 870-889.

Mitchell, R. J., Karron, J. D., Holmquist, K. G. \& Bell, J. M. 2004: The influence of Mimulus ringens floral display size on pollinator visitation patterns. - Functional Ecology 18: 116-124.

Nabhan, G. P. \& Buchmann, S. L. 1997: Services provided by pollinators. - In: Daily, G. (ed.), Nature's services. Island Press, Washington D. C. 133-150 pp.

O’Neill, K. M., O’Neill, R. P., Blodgett, S. \& Fultz, J. 2004: Composition of pollen loads of Megachile rotundata in relation to flower diversity (Hymenoptera: Megachilidae). - Journal of the Kansas Entomological Society 7: 619-625.

Potts, S. G., Petanidou, T., Roberts, S., O’Toole, C., Hulbert, A. \& Willmer, P. 2006: Plant-pollinator biodiversity and pollination services in a complex Mediterranean landscape. - Biological Conservation 129: 519-529.
Price, M. N., Waser, N. M., Irwin, R. E., Campbell, D. R. \& Brody, A. K. 2004: Temporal and spatial variation in pollination of a montane herb: a seven-year study. Ecology 86: 2106-2116.

Rocha, M., Good-Ávila, S. V., Molina-Freaner, F., Arita, H. T., Casillo, A., García-Mendoza, A., Silva-Montellano, A., Gaut, B. S., Souza, V. \& Eguiarte, L. E. 2006: Pollination biology and adaptive radiation of agavaceae, with special emphasis on the genus Agave. - Aliso 22: 329-344.

Sahli, H. F. \& Jeffrey, K. 2007: Visitation, effectiveness, and efficiency of 15 genera of visitors to wild radish, Raphanus raphanistrum (Brassicaceae). - American Journal of Botany 94: 203-209.

Staton, M. L. 1987: Reproductive biology of petal colour variations in wild populations of Raphanus sativus I. Pollinator response to colour morphs. - American Journal of Botany 74: 178-187.

Strickler, K. 1996: Seed and bee yields as a function of forager populations: Alfalfa pollination as a model system. - Journal of the Kansas Entomological Society 69: 201-215.

Tan, J. J., Wang, S. Y. \& Zhou, H. Z. 2005: Fauna sinica, Insecta, Coleoptera, Eumolpidae. - Science Press. Beijing, China.

Thomson, J. D. \& Thomson, B. A. (1992) Ecology and evolution of plant reproduction: new approaches. Chapman \& Hall, New York. 1-24 pp.

Thompson, J. D. 2001: How do visitation patterns vary among pollinators in relation to floral display and floral design in a generalist pollination system? - Oecologia 126: 386-394.

Viands, D. R., Sun, P. \& Barnes, D. K. 1988: Pollination control: mechanical and sterility. - In: Hanson, A. A., Barnes, D. K. \& Hill, R. R. Jr. (eds.), Alfalfa and alfalfa improvement. - Agronomy Monograph 29: 931960.

Wang, X. J., Liu, H. P., Li, X. X., Song, Y., Chen, L. \& Jin, L. 2009: Correlations between environmental factors and wild bee behavior on alfalfa (Medicago sativa) in Northwestern China. - Environmental Entomology 38: $1480-1484$

Wang, X. J., Li, X. X., Zhang J. W., Feng, G. H., Zhang, S. Z., Huang, L. C., Zhuo, R. Y. \& Jin, L. 2011: Characterization of nine alfalfa varieties for differences in ovule numbers and ovule sterility. - Australian Journal of Crop Science 5: 447-452.

Wilson, P. \& Thomson, J. D. 1991: Heterogeneity among floral visitors leads to discordance between removal and deposition of pollen. - Ecology 72: 1503-1507.

Wu, Y. R. 1990: Descriptions of nine new species of Apoidea from Inner Mongolia. - Entomotaxonomia 7: 243-251.

Wu, Y. R. 2006: Fauna sinica, Insecta, 44: Hymenoptera. - Science Press, Beijing, China. 373 pp.

Yang X. K. 2005: Fauna of the west of Qinling Mountain and the South of Gansu. - Science Press. Beijing, China. 